\title{
O problema da afecção no pós-kantismo e a concepção de intuição empírica em Schopenhauer
}

\author{
The problem of the affection in the post-kantianism and the conception of \\ the empirical intuition in Schopenhauer
}

\author{
Daniel Quaresma F. Soares \\ Doutor em Filosofia pela Universidade de São Paulo (USP) \\ E-mail:danielquaresmasoares@gmail.com
}

Resumo: Este artigo começa apresentando de modo sintético elementos da polêmica em torno do chamado problema da afecção, ocorrida nos anos seguintes à publicação da Crítica $d a$ razão pura. Com esse fim, são reconstituídos brevemente alguns argumentos de Jacobi, Reinhold, Schulze e Fichte. Essa reconstituição serve de base à apresentação, em seguida, de como Schopenhauer interpreta historicamente o problema da afecção e, a seu modo, absorve suas exigências em componentes importantes de sua filosofia, procurando resolvê-lo por meio de sua concepção de intuição empírica. Como pano de fundo, a exposição desse movimento permite problematizar a autoproclamada rejeição total de Schopenhauer à filosofia pós-kantiana e, em contrapartida, evidenciar um elemento central da fidelidade schopenhaueriana ao projeto original da filosofia crítica.

Palavras-chave: Schopenhauer; Problema da afecção; Intuição empírica; Coisa-em-si.
Abstract: This article begins presenting in a synthetic way elements of the polemic involving the so-called "problem of affection", that occurred in the years following the publication of the Critique of Pure Reason. To this end, are briefly reconstituted some Jacobi, Reinhold, Schulze and Fichte's arguments. This reconstitution serves as the basis for the ensuing presentation of how Schopenhauer historically interprets the problem of affection and, in his way, absorbs its demands in important components of his philosophy, seeking to solve it by his conception of the empirical intuition. As a background, the exposure of this movement makes possible to problematize the self-proclaimed Schopenhauer's total rejection of the post-kantianism philosophy and, conversely, evinces a central element of the schopenhaurian fidelity to the original project of the critical philosophy.

Keywords: Schopenhauer; Problem of affection; Empirical intuition; Thing-in-itself. 


\section{4 verdadeira e séria filosofia ainda se encontra lá onde Kant a deixou. Em todo caso, não reconheço que tenha acontecido algo na filosofia,
entre ele e mim; por conseguinte, ligo-me imediatamente a ele"1. Já é} famosa essa afirmação da Crítica da filosofia kantiana, na qual o filósofo procura nos advertir sobre o modo como deveria ser historicamente considerado. Contudo, afora o espanto porventura suscitado por uma afirmação dessa espécie - como simplesmente desconsiderar um dos períodos tradicionalmente considerado dos mais férteis na história da filosofia alemã? -, sabemos hoje que devemos tomar aquela advertência cum grano salis. A vasta historiografia filosófica em torno da obra schopenhaueriana já nos mostrou que, descontadas as reiteradas ofensas e injúrias, é possível estabelecer algumas interfaces conceituais ou mesmo contraposições férteis entre a filosofia de Schopenhauer e o idealismo alemão. Com efeito, além dos três grandes idealistas (os "três conhecidos sofistas"2), também a importância de outros autores pós-kantianos, hoje menos conhecidos, impede-nos de aceitar sem ressalvas uma suposta filiação direta de Schopenhauer a Kant.

Neste artigo pretendemos, na esteira do trabalho de Maria Lúcia Cacciola ${ }^{3}$, chamar a atenção para o modo como alguns elementos de uma polêmica ocorrida nos anos que sucederam à publicação da Crítica da razão pura, a saber, o problema das coisas em si como afectantes, colaboram para a compreensão da concepção schopenhaueriana de intuição empírica, componente central de sua filosofia. Procuraremos mostrar como o filósofo de Danzig não apenas tomará conhecimento dessa polêmica mas, interpretandoa a seu modo, absorverá algo de suas exigências e procurará respondê-las na elaboração de sua filosofia.

Com esse intuito, começaremos por remontar, de modo esquemático e a mero título de introdução histórica, alguns momentos centrais do debate acerca do problema da afecção no pós-kantismo. Faremos algumas referências a Jacobi, Reinhold, Schulze e Fichte. A seguir, tomando por fio condutor uma passagem dos Fragmentos para a história da filosofia, apontaremos como esse debate permeia a teoria do conhecimento schopenhaueriana. Por último, tentaremos ainda apontar brevemente como, apesar da

\footnotetext{
${ }^{1}$ SCHOPENHAUER, A. CK, p. 525. Há muitas passagens semelhantes ao longo da obra schopenhaueriana. Nos Suplementos, por exemplo, o filósofo se refere ao "período da pseudofilosofia entre Kant e mim" (SCHOPENHAUER, A. WWV II, cap. 22, p. 375).

${ }^{2}$ SCHOPENHAUER, A. P I, Fragmentos para a história da filosofia, § 13, p. 75.

${ }^{3}$ CACCIOLA, M. L. M. O. Schopenhauer e a questão do dogmatismo.

0 problema da afecção no pós-kantismo e a concepção de intuição empírica em Schopenhauer
} 
absorção do debate pós-kantiano, Schopenhauer pretende permanecer - de um determinado modo, e sob um outro ponto de vista - fiel à pretensão de vincular-se diretamente a Kant e ao projeto original da filosofia crítica.

Em 1787, mesmo ano da publicação da segunda edição da Crítica da razão pura, Friedrich Heinrich Jacobi publica David Hume über den Glauben, oder Idealismus und Realismus, Ein Gespräch. No apêndice a essa obra Jacobi trata do idealismo transcendental kantiano ${ }^{4}$ e formula uma objeção que pretende atingir os pilares da crítica da razão. Tomando por base algumas passagens da Estética Transcendental (A 3637) e da Crítica do quarto paralogismo da psicologia transcendental (A 367-380), Jacobi alega que Kant teria deixado claro não ser possível falar em objetos exteriores a nós como coisas em si, mas apenas como fenômenos. Contudo, continua Jacobi, noutras passagens (e menciona expressamente, por exemplo, A 253, A 254 e A 494) Kant teria pressuposto coisas em si como causadoras de impressões em nossos sentidos, provocando sensações. Segundo essa interpretação, a concepção da sensibilidade como uma receptividade exige a referência a um "dado" que, afetando nosso ânimo, estaria na origem das sensações. A partir daí, Jacobi conclui finalmente que Kant recai numa aporia: por um lado, sem a pressuposição desse elemento externo na origem das sensações, o dado que nos afeta, não seria possível ao kantismo explicar a construção do conhecimento; por outro lado, a pressuposição de coisas em si afectantes da sensibilidade contraria os fundamentos do idealismo transcendental ${ }^{5}$.

Já ciente da objeção de Jacobi, Karl Leonard Reinhold, à época um dos maiores divulgadores do kantismo, publica sua Versuch einer neuen Theorie des menschlichen

\footnotetext{
${ }_{4}^{4}$ JACOBI, F. H. David Hume über den Glauben, oder Idealismus und Realismus. Ein Gespräch, p. 209-230.

${ }^{5}$ A importância de Jacobi ao formular o problema da afecção já fora reconhecida em 1797 por Fichte, que julga a demonstração de Jacobi como a "mais fundamentada e mais completa" (FICHTE, J. G. Sämmtliche Werke, Band I, p. 481). Posteriormente, o célebre neokantiano Hans Vaihinger também assinala a importância de Jacobi de modo enfático: "talvez o melhor e mais importante que em geral já foi expresso sobre Kant" (VAIHINGER, H. Kommentar zu Kants Kritik der reinen Vernunft, Band II, p. 36). Cassirer também ressaltou essa importância (CASSIRER, E. Das Erkenntnisproblem in der Philosophie und Wissenschaft der neueren Zeit, Band III, p. 17ss). A fim de evitar mal-entendidos, deixamos claro que não analisaremos aqui a justiça da objeção de Jacobi em relação ao sistema kantiano. Tal análise excederia o escopo dessa exposição, que se pretende apenas uma introdução histórica ao problema da afecção, tendo por objetivo sua relação com a filosofia schopenhaueriana. Interessa-nos aqui o fato de que a polêmica, incontestavelmente relevante nos anos seguintes à publicação da Crítica da Razão Pura, foi reconhecida e absorvida por Schopenhauer no horizonte de sua teoria do conhecimento. Caso se queira tratar de uma análise do problema da afecção mais direcionada à filosofia kantiana, deixamos como sugestão a interpretação de Gérard Lebrun, segundo a qual Kant varia o tratamento dado às coisas em si conforme o adversário a ser combatido, empiristas ou racionalistas (LEBRUN, G. A aporética da coisa em si, p. 51-68). O problema da afecção no pós-kantismo e a concepção de intuição empírica em Schopenhauer
} 
Vorstellungsvermögens em 17896. Antecipando o movimento que ganharia força no idealismo alemão, Reinhold busca um princípio unificador dos dois troncos do conhecimento apresentados pela Crítica da razão pura, sensibilidade e entendimento. Sua Filosofia Elementar encontra essa unidade no fato da consciência, apontando a faculdade representativa como condição necessária do conhecimento. Reinhold distingue entre condições internas e condições externas da representação. Sujeito representante e objeto representado são as condições externas, concebidos como referentes, distintos da mera representação. Já as condições internas, pertencentes à representação como partes constituintes, são aquilo que no interior da própria representação se referem ao sujeito representante e ao objeto representado. A condição interna que se refere ao sujeito deve ser chamada forma da representação; a que se refere ao objeto, por sua vez, denomina-se matéria da representação. Recorrendo ao exemplo da representação de uma árvore, Reinhold procura ilustrar a diferença entre objeto da representação e matéria da representação: vista de longe, a matéria da representação é ainda confusa; à medida que nos aproximamos, a representação ganha cada vez mais matéria, ao passo que o objeto representado permanece sempre o mesmo7. Já a forma da representação refere-se a um sujeito representante que, em si mesmo, é mero $\mathrm{X}$ desconhecido. $\mathrm{O}$ perfazer de cada representação exige a conjugação de forma e matéria, suas condições internas necessárias.

Inicialmente, Reinhold parece explicar a constituição do conhecimento sem a referência a coisas em si. Já que o correspondente do objeto na representação (sua matéria) exige uma forma interna à própria representação, deve-se evitar o equívoco de que as representações projetem coisas tais como são em si mesmas. A árvore como objeto tem necessariamente de ser diferente da representação da árvore: afinal, a representação pressupõe a elaboração da matéria pela forma. Por isso, Reinhold não hesita em afirmar que "nenhum representado, nenhum objeto, pode ser representado na sua forma independente da forma da representação, tal como ele é em si, só podendo

\footnotetext{
${ }^{6}$ Alguns excertos dessa obra, assim como da Segunda Introdução à doutrina-da-ciência, de Fichte, foram traduzidos para o português em Recepção da Crítica da Razão Pura (org. Fernando Gil). Sempre que nos referirmos a um dos trechos traduzidos, adotaremos a tradução e indicaremos, após referência ao original alemão, também o número da página na edição portuguesa. Nos casos de referência a trechos não traduzidos, a tradução é de nossa autoria.

7 REINHOLD, K. L. Versuch einer neuen Theorie des menschlichen Vorstellungsvermögens. Zweites Buch, $\S 15$, p. $230-231$.

O problema da afecção no pós-kantismo e a concepção de intuição empírica em Schopenhauer
} 
aparecer na consciência modificado pela forma da representação"8. Consequentemente, a concepção reinholdiana de representação exclui por definição a possibilidade de representarmos coisas em si. 0 filósofo expressa-se categoricamente em relação a isso: "A representação de um objeto na sua forma própria e independente da forma da representação, ou seja, da chamada coisa em si, é contraditória com o conceito de uma representação em geral. Isto significa que nenhuma coisa em si é representável"9.

Irrepresentável, logo incognoscível: pois, lembremos, a representação é condição do conhecimento. Se parássemos neste ponto, poderíamos concluir que Reinhold teria apresentado a constituição do mundo objetivo sem recorrência a coisas em si mesmas, afastando-se do problema da afecção. Mas não é esse o caso. Fiel, por um lado, ao projeto crítico kantiano, Reinhold pretende manter a concepção de coisas em si como indispensável à filosofia crítica. Afastando-se, por outro lado, da cautela e equivocidade da Crítica da razão pura ao tratar das coisas em si, Reinhold introdu-las declaradamente no fundamento do conhecimento.

O objeto representado reclama seu lugar. Tal objeto será concebido como o irrepresentável que fundamenta externamente aquilo que lhe representa no interior de cada representação. Reinhold é bastante claro a esse respeito:

Tal como os próprios objetos representáveis, as coisas em si também não podem ser negadas. Elas são esses mesmos objetos, na medida em que estes não são representáveis. Constituem esse algo que é o fundamento [zum Grunde liegen], exterior [ausser] à representação, da matéria de uma representação [...] A coisa em si e as suas qualidades, distintas da forma da representação, não só não são nada impossível, como até são algo indispensável à mera representação, porque nenhuma mera representação é pensável sem matéria, e nenhuma matéria sem algo exterior à representação e desprovido da forma da representação, ou seja, sem a coisa em si $^{10}$.

Hipostasiando a coisa-em-si em fundamento, Reinhold acaba por aplicar uma lente de aumento sobre aquela suposta aporia da filosofia kantiana e, como observaram Ernst Cassirer e Nicolai Hartmann, sua recaída em dogmatismo é inevitável ${ }^{11}$. A

\footnotetext{
${ }^{8}$ REINHOLD, K. L. Versuch einer neuen Theorie des menschlichen Vorstellungsvermögens. Zweites Buch, § 16, p. 240. Recepção da Crítica da Razão Pura: p. 188.

9 Idem, § 17, p. 244. Recepção da Crítica da Razão Pura: p. 191.

10 Idem, § 17, p. 248-249. Recepção da Crítica da Razão Pura, p. 194.

11 Após ressaltar que Kant tratou a questão das coisas em si com uma "escolhida cautela" [ausgesuchter Vorsicht], Hartmann assevera que "Reinhold falhou catastroficamente no ponto em questão, e com isso viu-se arrastado para o lado realista, sem ter a noção do alcance de sua inconsequência” (HARTMANN, N. 0 problema da afecção no pós-kantismo e a concepção de intuição empírica em Schopenhauer
} 
problemática terminologia do "dado" [gegeben], questionada por Jacobi, ganha inclusive maior destaque na letra de Reinhold, ajudando a alastrar a querela em torno do problema da afecção.

Em 1792 surge o ataque cético de Gottlob Ernst Schulze. Seu escrito polêmico Aenesidemus oder über die Fundamente der von dem Herrn Professor Reinhold in Jena gelieferten Elementar-Philosophie, como se depreende já pelo título, tenciona atacar o criticismo a partir do flanco escancarado por Reinhold. Seguindo a trilha da objeção de Jacobi, Schulze pretende evidenciar uma contradição entre os pressupostos da Estética Transcendental e as conclusões da Dedução Transcendental das categorias. Valendo-se como anteparo da interpretação reinholdiana ${ }^{12}$, o cético pode afirmar sem mais ressalvas que a Estética Transcendental sustenta-se sobre o pressuposto de coisas em si mesmas que, realiter existentes, afetam a sensibilidade, fornecendo-lhe seu material. A Dedução Transcendental, por sua vez, impede a aplicação de conceitos puros do entendimento (no caso em questão, segundo Schulze, os de causa e realidade) a objetos além da experiência possível. Portanto, nos mesmos moldes de Jacobi, Schulze parte do problema da afecção para diagnosticar uma contradição interna insolúvel para a crítica da razão.

A última intervenção para a qual gostaríamos de chamar a atenção neste debate é a de Fichte. Mesmo aprovando a tentativa reinholdiana de fundar a filosofia crítica a partir de um único princípio, Fichte desaprova o princípio escolhido por Reinhold, o fato da consciência [Tatsache des Bewusstseins]. Como sabemos, na doutrina-da-ciência o primeiro princípio não poderá ser um fato (Tatsache), e sim uma Tathandlung: o ato originário de autoposição do Eu.

Na Segunda Introdução à doutrina-da-ciência, Fichte dá razão às objeções de Jacobi e Schulze, afirmando que "o kantismo dos kantianos" acaba por admitir o “dogmatismo mais grosseiro, o qual pretende que as coisas em si provocam impressões

Die Philosophie des deutschen Idealismus, p. 27). Cassirer segue a mesma linha: “A recaída em dogmatismo é aqui evidente: pois o que se suprime é justamente o pensamento crítico fundamental, segundo o qual as condições do ser não são determináveis senão por meio das condições do saber" (CASSIRER, E. Das Erkenntnisproblem in der Philosophie und Wissenschaft der neueren Zeit, p. 53-54).

${ }^{12}$ Nicolai Hartmann sugere que o ataque de Schulze torna-se mais poderoso após a versão reinholdiana da doutrina de Kant. Ao aplicar impensadamente a categoria de causalidade sobre a coisa-em-si, a Filosofia Elementar tornou "fácil ao cético jogar Kant contra Kant" (HARTMANN, N. Die Philosophie des deutschen Idealismus, p. 17).

O problema da afecção no pós-kantismo e a concepção de intuição empírica em Schopenhauer 
em nós"13. Esse dogmatismo teria em sua origem uma má interpretação da Crítica. Segundo Fichte, se atentarmos para a obra de Kant constataremos que as coisas em si são meramente númenos, isto é, algo pensado por nós como complemento ao fenômeno, existentes apenas no pensamento. 0 disparate dogmático surge quando se pretende que este constructo inteligível atue sobre os sentidos. É justamente nesse "velho disparate" [Unfug] que Fichte, na Recension des Aenesidemus, identifica o fundamento do ceticismo renovado de Schulze e de todas as objeções que se levantaram contra a filosofia crítica. Segundo o autor da resenha, nem Kant nem Reinhold teriam ainda "se explicado de modo suficientemente alto e claro" contra tal disparate ${ }^{14}$.

Assim, embora Fichte não considere que esse disparate esteja legitimado pelo espírito da Crítica, o idealismo deve ser erigido de modo a eliminar qualquer resquício dogmático surgido a partir de sua letra ${ }^{15}$. Remontando passagens da Crítica da Razão Pura mencionadas por Jacobi, Fichte esclarece que nelas Kant está se referindo apenas ao objeto [Gegenstand] determinado pelo entendimento quando se vale de termos como afecção e receptividade. Os limites do pensamento não são ultrapassados: dizer que o objeto afeta significa dizer que ele é "apenas pensado enquanto afectante" [es wird nur gedacht als afficirend]. A receptividade da sensibilidade, por sua vez, significaria apenas o pensamento de "ser afectável em geral" [afficirbar überhaupt]. Assim, as objeções antikantianas não se dão conta de que aquele "dado" remete apenas a um "mero pensamento" [ein blosser Gedanke] como dado ${ }^{16}$.

O posicionamento face a esse problema contribuirá para que Fichte descarte a própria noção de coisa-em-si na construção de seu sistema. Tal posição transparece já na Recension des Aenesidemus:

A questão é justamente a de uma passagem do exterior ao interior [Übergange von dem Äussern zum Innern], ou vice-versa. A tarefa da filosofia crítica é, justamente, mostrar que não precisamos de uma passagem, que tudo o que ocorre em nosso ânimo há de explicar-se e compreender-se totalmente a partir dele mesmo [...] [a Filosofia Crítica]

\footnotetext{
${ }^{13}$ FICHTE. J. G. Sämmtliche Werke, Band I, p. 365. Recepção da Crítica da Razão Pura: p. 348.

${ }^{14}$ FICHTE. J. G. Sämmtliche Werke, Band I, p. 19.

15 Conforme o comentário de Fichte por Rubens Rodrigues Torres Filho: "isso só foi possível porque Kant fala ainda uma linguagem inocente: não se interroga sobre as condições de possibilidade de seu próprio discurso teórico, e somente a coerência do seu fazer (a eficácia da Crítica) pode suprir as deficiências do seu dizer (a presença de palavras como 'receptividade' ou 'coisa em si', pronunciadas sem ressalva)" (TORRES FILHO, R. R. O espírito e a letra, p. 105).

${ }^{16}$ FICHTE, J. G. Sämmtliche Werke, Band I, p. 487-488. Recepção da Crítica da Razão Pura: p. 351-352.

0 problema da afecção no pós-kantismo e a concepção de intuição empírica em Schopenhauer
} 
nos mostra o círculo do qual não podemos sair ${ }^{17}$.

Distanciando-se de Kant, Fichte acaba por assumir que o pensamento de uma coisa-em-si é autocontraditório. A partir daí, o passo seguinte ruma em direção ao idealismo decidido recomendado por Jacobi: incognoscível em Kant e irrepresentável em Reinhold, a coisa-em-si torna-se impensável em Fichte. No horizonte da doutrina-daciência a coisa-em-si significa, em certa medida, o absurdo de um Não-Eu que não está oposto a um Eu. Portanto, algo como uma coisa-em-si, existente e "independente de qualquer faculdade representativa" nada é senão " uma fantasia, um sonho, um nãopensamento"18.

Essa breve reconstituição de alguns elementos do debate acerca do problema da afecção será suficiente para o que nos importa aqui: averiguar determinados aspectos da recepção desse problema no interior da filosofia schopenhaueriana. Com esse intuito, acompanharemos doravante bem de perto um trecho do parágrafo 13 dos Fragmentos para a história da filosofia, publicados no primeiro volume dos Parerga e paralipomena. A relevância específica desse parágrafo para a questão do presente trabalho justifica-se pela dupla face mediante a qual o texto é construído: Schopenhauer apresenta sua compreensão a respeito do debate histórico em torno do problema da afecção e, ao mesmo tempo, expõe sua solução para o problema, relacionando-o com uma apresentação de sua própria filosofia; ou, mais precisamente, apresenta sua filosofia como o modo correto de solução para o problema pós-kantiano.

Segundo Schopenhauer, a admissão da coisa-em-si como "fundamento" dos fenômenos tornou-se o "calcanhar de Aquiles" da filosofia kantiana. Essa vulnerabilidade teria ensejado os ataques céticos de Schulze: "as inconsequências em que Kant se enredou por meio da via errada [fehlerhaften Gang] que tomou em vista disso foram-lhe demonstradas por Gottlob Ernst Schulze"19. Ainda segundo o autor d'O mundo como

\footnotetext{
${ }^{17}$ FICHTE. J. G. Sämmtliche Werke, Band I, p. 15.

18 Idem, p. 17.

${ }^{19}$ SCHOPENHAUER, A. P I, Fragmentos para a história da filosofia, § 13, p. 80. Para Schopenhauer o ataque antikantiano mais importante é certamente o de Schulze. Lembremos que Schulze foi professor de Schopenhauer em Göttingen. Na Crítica da filosofia Kantiana, por exemplo, Schopenhauer refere-se a Schulze como "o mais arguto" [scharfsinnigste] dos opositores de Kant (SCHOPENHAUER, A. CK, p. 550). Jacobi, por sua vez, é geralmente mencionado com referências irônicas, tais como "o grande filósofo ainda vivo" (SCHOPENHAUER, A. MVR I, Prefácio à primeira edição, p. 24) e, no mesmo sentido, MVR I, § 31, p. 240; ou ainda como representante de um novo realismo com feições espinosanas (por exemplo, WWV II, cap. 1 , p. 17 e WWV II, cap. 50, p. 828). 
Vontade e Representação, Reinhold "conduziu a defesa de Kant, embora sem particular sucesso"20. Dessa problemática emergiria diretamente a posição fichteana: "surge Fichte, que, já que a coisa-em-si estava em descrédito, preparou depressa um sistema sem qualquer coisa-em-si, rejeitando com isso a admissão de qualquer coisa que não fosse apenas nossa representação"21.

Sendo assim, Schopenhauer de certo modo legitima o problema da afecção ${ }^{22}$. A "via errada" adotada por Kant em relação à coisa-em-si deu margem às objeções antikantianas. Reinhold foi incapaz de corrigir a rota da filosofia crítica, culminando na depreciação e descarte da noção de coisa-em-si em Fichte. Esse horizonte histórico influenciará o horizonte de possibilidades para a constituição da filosofia schopenhaueriana, já que o filósofo não pretende de modo algum abrir mão da noção de coisa-em-si. Mesmo reconhecendo alguma legitimidade no problema pós-kantiano da afecção, Schopenhauer declara vincular-se diretamente a Kant, desconsiderando as mais de três décadas transcorridas entre a primeira formulação do problema da afecção e a publicação d'O mundo como vontade e representação. Aparentemente, isso nos leva a ter de escolher uma entre duas das seguintes opções: já que a noção de coisa-em-si é imprescindível para a constituição da filosofia schopenhaueriana, ou aquele "ligo-me imediatamente" a Kant significa conservar em seu próprio pensamento a "via errada" que ensejara os ataques antikantianos e o descrédito da própria noção de coisa-em-si, ou Schopenhauer teve de elaborar sua filosofia operando aquela correção de rota necessária, malograda por Reinhold. A primeira opção é, como se verá logo adiante, inadequada ao caso. A segunda, por sua vez, levaria-nos a constatar que Schopenhauer

\footnotetext{
${ }^{20}$ SCHOPENHAUER, A. P I, Fragmentos para a história da filosofia, § 13, p. 80. As referências a Reinhold na obra de Schopenhauer são, de maneira geral, positivas. No escrito sobre a filosofia universitária, Schopenhauer denomina Reinhold "o primeiro apóstolo de Kant", reconhecendo seu esforço de absorver o espírito da Crítica da Razão Pura (SCHOPENHAUER, A. P I, Über die Universitäts-Philosophie. SW IV, p. 209). Já no escrito Sobre o fundamento da moral, Schopenhauer - apesar de atribuir a Reinhold uma má interpretação, antropológica e empírica, do imperativo categórico kantiano - menciona o ensaio reinholdiano Beiträgen zur Übersicht der Philosophie im Anfang des 19. Jahrhunderts como "bem digno de ser lido" (SCHOPENHAUER, A. M, § 6, p. 54).

${ }^{21}$ SCHOPENHAUER, A. P I, Fragmentos para a história da filosofia, § 13, p. 84. Embora essa interpretação seja certamente questionável, devemos lembrar que Schopenhauer vê no sistema de Fichte um dogmatismo do sujeito, isto é, a concepção da relação entre Eu e Não-Eu como uma relação do fundamento ao fundado. Sobre isso, ver por exemplo: MVR I, § 7, p. 70; P I, Skizze einer Geschichte der Lehre vom Idealen und Realen, p. 37; SG (segunda edição), § 21, p. 105; P II, Sobre a filosofia e seu método, § 28, p. 73. ${ }^{22}$ No mesmo sentido da referência a Schulze no parágrafo 13 dos Fragmentos para a história da filosofia é a passagem correspondente na Crítica da filosofia kantiana: se o "principal defeito" da obra kantiana foi "a introdução da coisa-em-si pelo modo como escolheu", sua "inadmissibilidade foi demonstrada em detalhes por G.E Schulze em Enesidemo e logo reconhecida como o ponto fraco de seu sistema" (SCHOPENHAUER, A. CK, p. 547-548). 
admite menos do que deveria sobre a importância da absorção do debate pós-kantiano em sua filosofia. Mas não haveria, porventura, uma terceira via?

Após apresentar sua compreensão histórica do problema da afecção, Schopenhauer anuncia de modo inequívoco e enfático suas pretensões seguintes: "Quero aqui pôr em relevo claramente, de uma vez por todas, a meu modo, o propriamente essencial da questão que está no fundo de toda a controvérsia, independentemente da concepção que Schulze tem dela". E a primeira frase dessa posição definitiva é: "Kant nunca forneceu uma rigorosa dedução da coisa-em-si"23. Partindo desse diagnóstico, Schopenhauer primeiramente buscará evidenciar a gênese daquela via errada escolhida por Kant. Segundo o filósofo de Danzig, Kant ensina que nosso conhecimento empírico é composto por dois elementos: um comprovadamente subjetivo e outro em cuja origem repousa a questão problemática. Assim, o autor da Crítica da Razão Pura apontou como subjetivos os elementos a priori de nosso conhecimento, a forma dos fenômenos, mas não pôde fazer o mesmo em relação à matéria dos fenômenos, aquilo que neles se manifesta. Eis por que, segundo Schopenhauer, "Kant não tem a menor dúvida em deixar essa matéria do fenômeno para a coisa-em-si-mesma, vendo-a assim como vinda de fora [aussen] - isso porque ela teria de vir de algum lugar ou, como se expressa Kant, tem de ter algum fundamento"24. Considerada por um determinado viés, a saber, o que pressupõe haver algo manifestante por detrás das manifestações fenomênicas, a pressuposição da coisa-em-si por Kant é legítima. Não é essa pressuposição que Schopenhauer reprova, mas sua sustentação no interior da doutrina kantiana. Afinal, tal pressuposição torna-se "insustentável, quando seu único argumento [...] é examinado corretamente e reconduzido à sua origem" 25 .

O erro do argumento kantiano, segundo Schopenhauer (juntando-se a Jacobi e Schulze), seria exatamente o que suscitou o problema da afecção: radicar aquela matéria na origem das impressões dos sentidos. Eis o ponto onde Schopenhauer pretende ter ido além de Kant e solucionado o problema pós-kantiano. A explicação fornecida na continuação da passagem dos Fragmentos traz apenas algumas poucas linhas, mas o próprio filósofo nos indica onde julga ter exposto melhor a resolução da questão: "todo esse processo se encontra detalhada e profundamente exposto na segunda edição de

${ }^{23}$ SCHOPENHAUER, A. P I, Fragmentos para a história da filosofia, § 13, p. 80.

${ }^{24}$ Idem, p. 81.

${ }^{25}$ Idem, p. 82.

0 problema da afecção no pós-kantismo e a concepção de intuição empírica em Schopenhauer 
minha dissertação Sobre o princípio de razão, § 21"26.

Esse parágrafo trata sobretudo de explicar o papel do entendimento na constituição da intuição empírica. Pouco antes, no parágrafo 19, o filósofo estabelecera uma distinção entre representações imediatas e representações completas, também denominadas "coisas reais" [reale Dinge]: as representações imediatas apresentam-se apenas sob a forma do sentido interno, no tempo; já as representações completas apresentam-se sob a forma do sentido interno $e$ do sentido externo, ou seja, também no espaço. Essa distinção servirá de base à distinção entre sensações e intuições. Schopenhauer conceberá as sensações como meras modificações nos órgãos dos sentidos, constituídas apenas sob a forma do sentido interno e a nada remetendo de exterior $^{27}$. Já as intuições dão-se no tempo $e$ no espaço, por isso remetendo a algo fora de nós. A passagem da sensação à intuição será realizada por intermédio do entendimento, cuja única forma (e não categoria, pois não é conceito puro) é a causalidade. A operação própria do entendimento consiste em ligar um efeito em nós (a sensação) à sua causa, um objeto. Concebendo o objeto como uma representação completa, aquela sob a forma espaço-temporal, fica claro que essa exterioridade é apenas o modo de aparição das representações submetidas também à forma do sentido externo: “é assim que surge para ele [entendimento] o fora [das Ausserhalb], cuja possibilidade é precisamente o espaço" 28 . Desse modo, tudo se passa entre representações: as coisas reais não precisam ser explicadas a partir da pressuposição de coisas em si afectantes.

No escopo do presente trabalho, o que nos interessa especialmente na concepção schopenhaueriana da constituição da intuição empírica é a questão da origem da sensação. Mesmo que o filósofo porventura recaia noutros problemas decorrentes dessa concepção ${ }^{29}$, é inegável que sua explicação pretende eliminar a necessidade de recorrer

\footnotetext{
${ }^{26}$ Idem, ibidem.

27 “Pois que coisa pobre, de fato, é a mera sensação! Mesmo nos órgãos dos sentidos mais nobres, ela é apenas um sentimento local, específico, capaz de algumas variações no interior de sua espécie, entretanto sempre um sentimento em si subjetivo e, como tal, não podendo conter nada de objetivo, portanto nada que se assemelhe a uma intuição" (SCHOPENHAUER, A. SG, § 21, p. 68).

${ }^{28}$ Idem, p. 69.

29 Uma questão relevante, por exemplo, seria analisar se a explicação schopenhaueriana não incorre numa petição de princípio entre sensações e objetos. Para que haja sensações é preciso que os objetos as causem: afinal, as sensações serão reconhecidas pelo entendimento como efeitos dos objetos. Ao mesmo tempo, para que haja objetos é preciso que haja sensações: afinal, é apenas na passagem dos efeitos (sensações) às causas que os objetos podem surgir. Tais objetos, embora causas das sensações, só se constituem no conhecimento quando o entendimento - a partir dos efeitos - remonta às causas. Mesmo recorrendo a uma possível distinção entre anterioridade lógica e cronológica, não fica totalmente claro se a relação entre sensação e objeto resta suficientemente explicada. Janaway também levanta essa questão: "Aparentemente, esse objeto empírico, e mesmo material, surge da transição da sensação à causa inferida, 0 problema da afecção no pós-kantismo e a concepção de intuição empírica em Schopenhauer
} 
à afecção de coisas em si sobre a sensibilidade e, desse modo, apresentar sua solução ao problema pós-kantiano.

É isso o que nos mostra a continuação daquela passagem dos Fragmentos. Exatamente após a remissão à Quádrupla raiz, Schopenhauer frisa os resultados importantes de sua concepção da constituição da intuição empírica para o debate em torno do problema da afecção. Se o calcanhar de Aquiles kantiano era pressupor coisas em si na origem das sensações, agora "a impressão dos sentidos [...] fornece indiscutivelmente toda a matéria para a intuição empírica, é de fato algo totalmente subjetivo" 30 .

Schopenhauer certamente tem consciência de procurar responder ao problema da afecção no interior de sua obra. $\mathrm{O}$ autor dos Fragmentos não se apresenta como um historiador da filosofia, imparcial: ao contrário, o filósofo anuncia que irá fornecer "de uma vez por todas, a meu modo", o fundamento da controvérsia, remetendo-nos à sua própria obra, porque pretende ter absorvido e, segundo sua perspectiva, resolvido a questão mediante sua concepção da intuição empírica. Por meio daquela estrutura que denominamos de dupla face, Schopenhauer elabora sua exposição de modo a antepor as conclusões de sua concepção da intuição empírica aos princípios da filosofia kantiana: “a representação intuitiva e o nosso conhecimento empírico que nela se apoia não oferecem verdadeiramente nenhum elemento para a inferência de coisas em si, e Kant

que é trazida à tona pelo entendimento do sujeito. Ele existe apenas na intuição. Entretanto, a sensação supostamente existe antes (embora talvez não temporalmente) da operação do entendimento que é constitutiva da posição do objeto para o sujeito - então como os objetos podem ser a causa da sensação inicial?" (JANAWAY, C. Self and World in Schopenhauer's Philosophy, p. 159). Outro aspecto importante na passagem das sensações às intuições diz respeito ao papel do corpo na teoria do conhecimento schopenhaueriana. No parágrafo 21 da primeira edição da Quádrupla raiz, Schopenhauer denomina o corpo "objeto imediato". Por meio dessa expressão, o filósofo pretende ressaltar a função privilegiada do corpo na constituição da intuição empírica: o corpo é tanto a sede das sensações quanto uma intuição, um objeto empírico entre outros. Como aponta Schöndorf, esse duplo papel [Doppelrolle] permite ao corpo exercer uma espécie de função mediadora entre sensações e intuições (SCHÖNDORF, H. Der Leib im Denken Schopenhauers und Fichtes, p. 145). Essa ambivalência é relevante porque afasta a pressuposição de uma relação causal entre uma representação imediata e uma representação completa. Afinal, o entendimento só pode estabelecer relações causais entre duas representações completas, conformadas sob espaço e tempo (SCHÖNDORF, H. Idem, p. 146). Contudo, no parágrafo 22 da edição de 1847, Schopenhauer retifica sua terminologia, considerando inadequado denominar o corpo "objeto imediato". A retificação pretende esclarecer que, durante o processo de constituição da intuição empírica, o corpo não aparece ainda como objeto. O corpo será conhecido como mais um objeto entre objetos apenas quando dado na intuição empírica, ou seja, quando "suas partes agem sobre seus sentidos, portanto se o olho o vê, se a mão o toca” (SCHOPENHAUER, A. SG, § 22, p. 106). Mesmo que tal retificação elimine um dos elos do "duplo papel" dantes atribuído ao corpo, Schopenhauer continua a atribuir-lhe a função de "intermediário" [Vermittelnd].

30 SCHOPENHAUER, A. P I, Fragmentos para a história da filosofia, § 13, p. 82.

O problema da afecção no pós-kantismo e a concepção de intuição empírica em Schopenhauer 
não estava autorizado, de acordo com seus princípios, a admiti-las"31.

Operando aquela correção de rota, Schopenhauer tem a pretensão de promover uma espécie de reconciliação do pensamento kantiano consigo mesmo, após o filósofo de Königsberg ter enveredado pela "via errada". Assim, a concepção de coisas em si como afectantes seria um desvio em relação aos próprios princípios kantianos: valendo-se desses princípios, Schopenhauer pretende colocar Kant novamente de acordo com Kant. A interpretação schopenhaueriana do problema da afecção sustenta-se, em última instância, numa temática famosa do pós-kantismo: a distinção entre o espírito e a letra da obra de Kant. Observemos as palavras do filósofo:

A admissão de uma coisa-em-si detrás dos fenômenos, de um caroço real sob tantas cascas, não é de nenhum modo inverídica, e seria muito mais absurda a negação dela. Mas apenas a maneira [Art] pela qual Kant introduziu uma tal coisa-em-si e procurou uni-la com seus princípios é que foi errônea. No fundo foi apenas sua exposição [Darstellung] (tomada esta palavra no seu sentido mais abrangente) da questão, não ela própria, que foi derrubada pelos seus opositores ${ }^{32}$.

O debate pós-kantiano acabou por tomar argumenta ad hominem por argumenta ad rem. 0 diagnóstico que identifica a origem do problema na letra kantiana permite-nos vislumbrar, como que concentradamente, alguns posicionamentos de Schopenhauer em relação a diferentes adversários. Tais posicionamentos apontam para diferentes aspectos daquilo que o filósofo pretende ser sua fidelidade a Kant, em detrimento dos póskantianos. Primeiro, e mais óbvio: esse diagnóstico lhe permite afirmar que as objeções antikantianas atingiam apenas a exposição da Crítica, não seus fundamentos. Desse modo, sem necessidade de deslegitimar totalmente o problema (cuja resolução é importante para uma filosofia que, como a de Schopenhauer, pretende-se legatária do idealismo transcendental), identifica-se seu vício de origem numa má interpretação, preservando o conjunto do pensamento kantiano: "confundiu-se a exposição kantiana com a essência da coisa, acreditou-se que, estando aquela refutada, também esta o estaria"33. Em segundo lugar: conservando o espírito da Crítica e, ao mesmo tempo, concedendo alguma legitimidade ao problema, Schopenhauer justifica a necessidade de apresentar sua própria versão da correção de rota necessária, sem precisar abrir mão de

\footnotetext{
${ }^{31}$ Idem, p. 83.

32 Idem, p. 79.

${ }^{33}$ Idem, p. 84.

0 problema da afecção no pós-kantismo e a concepção de intuição empírica em Schopenhauer
} 
pressupostos maiores da filosofia crítica. Terceiro: aquele diagnóstico permite apontar como ilegítimo o abandono da noção de coisa-em-si perpetrado por Fichte. Tal posicionamento não é de pouca relevância porque, em última análise, Schopenhauer detecta nesse abandono um trecho da certidão de nascimento do idealismo alemão: "declarou-se a filosofia de Kant como insustentável devido aos ataques de Schulze - Com isso o caminho ficou livre para os sofistas e para os cabeças-de-vento"34 (a partir deste ponto do parágrafo, Schopenhauer inicia as ofensas de praxe a Fichte, Schelling e Hegel). Quarto, último e mais relevante: para Schopenhauer, um dos traços mais importantes de sua fidelidade ao espírito kantiano é a conservação da noção de coisa-em-si em sua própria filosofia.

Portanto, detectada a "via errada" trilhada por Kant, trata-se de corrigir a rota por meio de dois movimentos em sequência. Primeiramente, o que nos interessou mais de perto aqui: eliminar a pressuposição de coisas em si na concepção da intuição empírica. Em seguida, indicar afinal a via correta. É isso o que encontramos também na continuação dos Fragmentos. Após ressaltar, em relação ao calcanhar de Aquiles kantiano, que a coisa-em-si "nunca mais pôde ser alcançada por essa via", o filósofo acrescenta que "só se pode chegar à coisa-em-si se, de uma vez por todas, desloca-se o ponto de vista [Standpunkt verlegt]"35.

Como sabemos, o ponto de vista que possibilitará a descoberta da vontade recusará a concepção da coisa-em-si como fundamento do fenômeno. Não se abordará mais a coisa-em-si pela via da origem da intuição empírica, mas pela autoconsciência e sua relação privilegiada com o corpo. A inspeção da autoconsciência descobrirá que os atos de vontade aparecem objetivamente como atos corporais, colocando em marcha a metafísica da Vontade. No contexto do presente trabalho, porém, interessa-nos ressaltar o que está na raiz dessa mudança de rota. Não é por acaso que, num parágrafo que promete em seu título apresentar "Ainda alguns esclarecimentos sobre a filosofia kantiana", Schopenhauer apresenta o problema da afecção entremeado por uma apresentação de importantes elementos constituintes de sua própria filosofia. Valendose dessa dupla face, Schopenhauer pretende fundamentalmente apresentar sua filosofia como a correção da via kantiana de acesso às coisas em si, resolvendo a seu modo o

\footnotetext{
34 Idem, ibidem.

${ }^{35}$ Idem, p. 83, em itálico no original.

0 problema da afecção no pós-kantismo e a concepção de intuição empírica em Schopenhauer
} 
problema da afecção: "só se pode, portanto, chegar a esta via por um caminho totalmente diferente do conhecimento objetivo, que permanece mera representação, ou seja, pedindo ajuda à autoconsciência do sujeito do conhecimento". E o filósofo não pretende que essa seja apenas uma correção dentre muitas possíveis, mas a correção: "Esse é o caminho que percorri e é o único certo, o portal estreito para a verdade"36.

Decerto que a "dedução" (para ficarmos com o termo schopenhaueriano) da coisa-em-si a partir da autoconsciência e do corpo trará consigo outros dilemas teóricos. Se adotarmos uma perspectiva estritamente kantiana, talvez não seja injusto afirmar que essa via não parece menos dogmática que a pressuposição de coisas em si como afectantes: afinal, a Crítica da razão pura já alertava que o caminho da autoconsciência não nos autoriza a dar um passo sequer em direção à determinação de coisas em si mesmas $^{37}$. Contudo, se concedemos algum crédito à perspectiva schopenhaueriana, percebemos que a manutenção da distinção entre coisas em si e fenômenos testemunha sua fidelidade a um dos pilares mais essenciais do projeto crítico.

Como a Crítica da filosofia kantiana enfatiza que "o maior mérito de Kant é a distinção entre fenômeno e coisa-em-si"38, dissolver essa duplicação dos pontos de vista significaria arruinar o próprio espírito da filosofia crítica. Embora o debate pós-kantiano alerte Schopenhauer para a necessidade de explicar a representação apenas pela própria representação, sem recorrer a coisas em si para a constituição da intuição empírica, isso não deixa de ser uma explicação restrita ao ponto de vista do fenômeno. Pois, mesmo que a filosofia schopenhaueriana não possua exatamente uma razão prática (em sentido kantiano), nem por isso se deve subestimar a importância do domínio moral. E apenas a partir da coisa-em-si, descoberta como Vontade, será possível atribuir um significado moral a nossas ações ${ }^{39}$. Eis um modo enviesado pelo qual Schopenhauer procura vincular-se "imediatamente" ao essencial do projeto crítico.

Chegamos, portanto, a uma via intermediária por meio da qual Schopenhauer pode tanto se arrogar ter corrigido a "via errada" ensejada pela letra kantiana quanto, em detrimento do debate pós-kantiano, vincular-se diretamente a Kant num sentido

\footnotetext{
${ }^{36}$ Idem, p. 84, em itálico no original.

37 Ver, por exemplo, Crítica da razão pura: B 152-153 e B 158.

38 SCHOPENHAUER, A. CK, p. 526.

39 Procurando rechaçar "razões extra-filosóficas" (tais como as alegadas, inclusive, por Schopenhauer) para a suposta recaída kantiana em dogmatismo na segunda edição da Crítica da Razão Pura, Rubens Rodrigues Torres Filho mostra a importância crucial dessa dupla significação das coisas em geral para o projeto crítico kantiano, a saber, a possibilidade de conferir um lugar à moral (TORRES FILHO, R. R. Dogmatismo e Antidogmatismo: Kant na sala de aula, p. 67-86).

0 problema da afecção no pós-kantismo e a concepção de intuição empírica em Schopenhauer
} 
fundamental. Mas, diferentemente do que admite o filósofo, essa via intermediária é possível menos porque ele não reconhece nada relevante no período transcorrido entre sua obra e a de Kant, e mais porque pretende ter absorvido as exigências e resolvido um dos grandes problemas pós-kantianos, resgatando assim o "maior mérito" e o espírito da filosofia crítica.

\section{Referências bibliográficas}

CACCIOLA, Maria Lúcia Mello e Oliveira. Schopenhauer e a questão do dogmatismo. São Paulo: Edusp, 1994.

CASSIRER, Ernst. Das Erkenntnisproblem in der Philosophie und Wissenschaft der neueren Zeit, Band III. Berlin: Verlag Bruno Cassirer, 1920.

FICHTE, Johann Gottlieb. Sämmtliche Werke. Erster Band. Berlin: Veit und Comp., 1845.

GIL, Fernando. Recepção da crítica da razão pura: antologia de escritos sobre Kant (1786-1844). Trad. Irene Borges Duarte e Fernanda Portela. Lisboa: Calouste Gulbenkian, 1992.

HARTMANN, Nicolai. Die Philosophie des deutschen Idealismus. Berlin: Walter de Gruyter, 1960. JACOBI, Friedrich Heinrich. David Hume über den Glauben, oder Idealismus und Realismus. Ein Gespräch. Ulm: Wohler, 1795.

JANAWAY, Christopher. Self and World in Schopenhauer's Philosophy. Oxford: Oxford University Press, 1989.

KANT, Immanuel. Kritik der reinen Vernunft. Nach der ersten und zweiten Original-Ausgabe neu herausgegeben von Raymund Schmidt. Hamburg: F. Meiner, 1956.

. Crítica da razão pura. Trad. Manuela Pinto dos Santos e Alexandre Fradique Morujão. Lisboa: Calouste Gulbenkian, 2001.

LEBRUN, Gérard. A aporética da coisa em si. In: Sobre Kant (Org. Rubens Rodrigues Torres Filho). São Paulo: Iluminuras, 2001, p. 51-68.

REINHOLD, Karl Leonard. Versuch einer neuen Theorie des menschlichen Vorstellungsvermögens. Zweite Auflage. Prag und Jena: C. Widtmann und J. M. Mauke, 1795.

SCHÖNDORF, Harald. Der Leib im Denken Schopenhauers und Fichtes. München: Johannes Berchmans, 1982.

SCHOPENHAUER, Arthur. Sämtliche Werke (org. Löhneysen) em 5 volumes. Stuttgart/Frankfurt am Main: Suhrkamp, 1986. 2005 .

O mundo como vontade e como representação. Tomo I. Trad. Jair Barboza. São Paulo: Unesp,

Fragmentos para a história da filosofia. Tradução, apresentação e notas de Maria Lúcia Cacciola. São Paulo: Iluminuras, 2003.

. Sobre o fundamento da moral. Trad. Maria Lúcia Mello Oliveira Cacciola. São Paulo: Martins Fontes, 2001.

. Sobre a filosofia e seu método. Trad. Flamarion C. Ramos. São Paulo: Hedra, 2010.

SCHULZE, Gottlob Ernst. Aenesidemus oder Über die Fundamente der von dem Herrn Professor Reinhold in Jena gelieferten Elementar-philosophie. Berlin: Reuther und Reichard, 1911.

TORRES FILHO, Rubens Rodrigues. O espírito e a letra. São Paulo: Ática, 1975.

. Dogmatismo e antidogmatismo: Kant na sala de aula. Cadernos de Filosofia Alemã, São Paulo, n. 7, 2001, p. 67-86.

VAIHINGER, Hans. Kommentar zu Kants Kritik der reinen Vernunft. Stuttgart/Berlin/Leipzig: Union Deutsche Verlagsgesellschaft, 1922. 
Recebido: 06/04/17 Received: 04/06/17

Aprovado: 02/07/17 Approved: 07/02/17 